\title{
Negritud, cumbite y socialismo \\ en Gobernadores \\ del rocío, de \\ Jacques Roumain
}

\section{Negritude, cumbite and socialism}

\section{in Jacques Roumain's}

Masters of the dew

\section{Clinton Ramírez*}

Universidad Sergio Arboleda, Colombia

Ivethe Noriega $* *$

Colegio Fundación Pies Descalzos de Barranquilla, Colombia

DOI: http://dx.doi.org/10.15648/cl.25.2017.5

* Docente Catedrático Universidad Sergio Arboleda. Magíster en Literatura Hispanoamericana y del Caribe.

** Magíster en Literatura Hispanoamericana y del Caribe. Docente Colegio Fundación Pies Descalzos de Barranquilla. libelula_zen@yahoo.es 


\section{Resumen}

Más que la exaltación del paisaje y la cultura del negro haitiano, en la línea del Indigenismo, Gobernadores del rocío (1944) invita a examinar con ojo crítico sus prácticas culturales y sus contradicciones internas. Para el autor haitiano, el vudú y las rencillas internas limitan el valor de las fuerzas comunitarias a la hora de afrontar la sequía, la deforestación, el hambre y la lucha por la liberación. El cumbite, a diferencia del vudú, cuyo valor cultural no ignora, emerge como la fuerza comunitaria a partir de la cual podría accederse a formas de organización horizontal -raciales y de clase-, conducentes a la lucha contra la explotación colonial y capitalista. EI socialismo es, según la ideología de Manuel, esa forma superior de organización política a la que debían adherir los negros haitianos y del Caribe con miras a superar la alienación y erradicar la explotación capitalista. El vudú sería una práctica inmovilista y el cumbite la fuerza plataforma de una utopía más amplia y movilizadora. Esta reserva no impide, sin embargo, que el vudú alcance en la novela, en tanto recurso literario, una alta eficacia estética, como propone Margarita Mateo Paler en su lectura mítica de la obra.

\section{Palabras clave}

Indigenismo, negritud, vudú, cumbite, socialismo.

\section{Abstract}

Beyond the exaltation of landscape and the culture of the Haitian afro descendant, Governors of the Dew (1944) invites the reader to examine the cultural practice and inner contradictions of that population. For his author voodoo and inner quarrels limit the value of communal forces at the moment of facing droughts, deforestation, starvation and the fight for liberation. Cumbite, despite voodoo (to which he assigns its due value) emerges as the communal force through which you can access to horizontal ways of class and racial organization that lead to the struggle against colonial and capitalist exploitation. Socialism is, based on Manuel's ideology, that way of superior political organization to which Haitian and Caribbean blacks should adhere so as to overcome alienation and eradicate capitalist exploitation. Voodoo is presented as an ecstatic practice whereas cumbite becomes the best and most dynamic utopia. That drawback of voodoo does not impede it to reach in the novel, as a literary resource, a high esthetic efficacy, following Margarita Mateo Palmer's mythic reading of this work.

\section{Key words}

Indigenism, negritude, vudu, cumbite socialism. 


\section{Introducción}

Este artículo examina las relaciones entre negritud, cumbite y socialismo en Gobernadores del rocío (1944), la emblemática novela del haitiano Jacques Roumain (1907-1944). La novela, adscrita a la Escuela Indigenista, comparte y hace explícito en líneas generales el programa de este movimiento de recuperar los valores propios como base para el desarrollo cultural y político. Tal tarea de rescate correspondería a la etnografía, la literatura y el arte, en la función de medios que generarían conocimiento, conciencia estética y acción política.

En Gobernadores del rocío, el autor supera los límites de quienes, al interior del Indigenismo, creyeron que el deber del arte que propugnaban culminaba con la glorificación de la vida campesina haitiana y de sus raíces africanas. Para Jacques Roumain la literatura debía cumplir una tarea más crítica y movilizadora. Podía incorporar la fuerza de la inventiva popular y el mito mágico religioso, ahondar en los conflictos internos de los pueblos negros del país, pero pensando siempre en la oferta de salidas comunitarias y políticas en la línea del socialismo, en lugar de glorificar el vudú, fuente de superstición y resignación que impedía a los negros asumir plenamente su destino. El vudú podría ser un recurso estético, pero en la realidad, operaba como un valor inhibitorio en choque con el credo marxista que profesaba el autor haitiano.

El negro, para Roumain, es además de un campesino discriminado por el color de la piel, un hombre explotado, víctima de las relaciones capitalistas y de los prejuicios de la burguesía mulata haitiana, aliada del colonialismo y el imperialismo invasor. Por ello, la vindicación de la cultura del negro haitiano tiene que ir acompañada de la acción política contra la explotación capitalista, porque el negro es también un proletario, sobre todo un explotado que debe movilizar distintas prácticas comunitarias y políticas de lucha para superar las rencillas internas y combatir al opresor, tanto interno como externo.

Así, ante la crisis ambiental, la pobreza, el hambre y las diferencias irreconciliables que sufren los negros de Fonds Rouge 1 , el pueblo de la ficción, Manuel,

1 Fonds Rouge, como tal, no existió en la geografía haitiana. Sería más bien una metáfora alusiva a un pueblo haitiano que ha superado sus crisis de sequía, espirituales y políticas. En cuanto palabra símbolo, "recrea la realidad" y contiene "su opuesto a la vez", anota Michaelle Ascencio en el Prólogo a la edición de la novela publicada en la Biblioteca Ayacucho, 2004, pp.IX-X. Aludiría la denominación a la fiesta que animará al pueblo una vez logren, mediante el cumbite, controlar el agua, es decir, convertirse en gobernadores del rocío, de la irrigación. 
el héroe sacrificado de la novela, propone a los suyos salidas que trascienden el cumbite y desestiman la práctica del vudú en tanto intercesión de los dioses. Adiestrado en las disputas sindicales en Cuba, donde trabajó durante quince años en los cañaverales, sabe que la fuerza comunitaria del cumbite ayudará a superar la crisis de la comunidad y preparará el camino hacia formas superiores de lucha: la organización sindical, la huelga y la política. En este sentido, la novela, si bien invoca en la lucha una institución comunitaria básica de los campos haitiano, el cumbite, y tolera la práctica del vudú, cuya ceremonia describe la novela ampliamente, deja claro que estas prácticas no son suficientes de cara a superar la alienación cultural de la comunidad.

Si bien la obra incorpora la dimensión mítica del vudú, en tanto reflejo de una conciencia mágico-religiosa inherente a los pueblos haitianos, la obra es crítica frente al limitado alcance de las mismas en la solución de los problemas como la sequía, la deforestación, las rencillas personales y el hambre. Es aquí, frente a la necesidad de encontrar salidas distintas al vudú, donde emerge la fuerza del cumbite, entendida como una etapa de organización que debe desencadenar en formas de acción más amplias, integradoras: la lucha contra la explotación económica y política y no solo la simple lucha contra el racismo. Esta orientación ideológica inscribe la novela, sin duda, en la línea materialista e histórica, que entiende la lucha del negro en términos políticos y no solo raciales. Esta idea motriz es la que Manuel intenta vender a una comunidad atada al vudú, dividida por la sangre y a expensas de las autoridades y especuladores del comercio. Al asumir la lucha contra la resignación, contra el odio y contra los explotadores, no es extraño que Manuel, a la vista de unos y otros actores, aparezca como el negro que estuvo afuera, portador de ideas ajenas a la comunidad y subversivo del orden. En esta lucha contará con el apoyo de Laurélien y Anaísa, muchacha hija de la familia enemiga, de quien se enamora y le corresponde. Serán sus aliados en el afán de buscar el agua, alcanzar la paz y traer de vuelta la prosperidad a la aldea. El amor de Manuel y Anaísa obrará como elemento de reconciliación pero, a su vez, atizará el odio de Gervilen, primo y pretendiente desairado de la muchacha, hijo del hombre asesinado por el tío de Manuel a raíz de una disputa de tierras.

\section{Indigenismo y negritud}

La ocupación norteamericana de Haití (1915-1934) significó un desplazamiento de las autoridades del país y el control de la nación por parte del invasor. El ocupante llegó a controlar las aduanas, los gastos del Estado, la formación policiva y alcanzó a imponer una nueva Constitución en 1918, medida con la que aseguró 
el derecho de propiedad inmueble de los extranjeros (Valero, 2005, pp.153-154). La medida facilitó el desplazamiento y despojo del campesinado de sus tierras, al que le quedaron dos caminos: proletarizarse al servicio de las transnacionales o emigrar en busca de otras oportunidades a Jamaica, Santo Domingo y Cuba, como sucede con Manuel en Gobernadores del rocío. Según el mismo Valero, la ocupación sistemática de la nación incluyó un ataque a las "manifestaciones populares, como el vudú", que "fueron objeto de una sistemática prohibición, persecución y destrucción" (p.154), debido a que durante la ocupación habían servido de depósito de cohesión y escudo de resistencia.

El Indigenismo, sería, para Arnaldo Valero, la respuesta intelectual de ciertos jóvenes estudiosos y artistas del país a la "indolencia y el oportunismo de la burguesía haitiana" (p.154), a la que muchos de ellos pertenecían, como es el caso de Jacques Roumain, distinguido miembro de la clase mulata rica y ligada al control del Estado haitiano.

El Indigenismo, congregado alrededor de la Revista Indigenista, nace en el seno de la propia clase dominante haitiana, cómplice y usufructuaria de la ocupación norteamericana. El alma y nervio de la reacción fue el médico y etnólogo Jean Price-Mars (1876-1969), autor de un conjunto de conferencias en el que denunció la forma en que el neocolonialismo norteamericano seguía empleando nociones racistas discriminadoras para invadir y someter países como Haití. En sus conferencias, recogidas luego bajo el título de Así habló tío conejo, se propuso demostrar, como señala Valero, que el pueblo de Haití, en particular, y los pueblos negros en general, estaban lejos de ser "desechos sin humanidad, sin historia, sin moral, sin religión a los cuales [habia] que infundir (...) nuevos valores" (p.155). El racismo, en su opinión, seguía vigente, en manos de los imperios occidentales, nuevos o viejos, y, alegó que la burguesía haitiana, constituida por los mulatos, sufrían de bovarismo colectivo al aceptar sin ninguna crítica los prejuicios raciales de Occidente, al considerar con repugnancia la cultura popular de los negros descendientes de los esclavos, en especial el vudú y su lengua creole (p.155).

La etnología sería para Jean Price-Mars, la ciencia que permitiría conocer la cultura negra haitiana y probar que esta hacía parte de una civilización negra africana que el colonialismo destruyó al invadir el continente y someter a la esclavitud a buena parte de su población. El negro pues, tenía que reivindicar su ancestro africano y asumir este pasado ancestral como parte del proceso de ruptura contra el colonialismo. Aceptarse, igualmente, haitiano, heredero de los negros esclavos 
de Santo Domingo (156). El propósito era claro: cuestionar la noción de civilización y progreso significaba oponerse a la ocupación norteamericana, desmontar sus supuestas razones.

La ocupación tuvo el efecto de hacerles ver a Jean Price-Mars, a Jacques Roumain y otros intelectuales y artistas, que la liberación del dominio político, cultural y económico tenía que comenzar por la búsqueda de la identidad y el reconocimiento de una cultura que muchos ignoraban. El Indigenismo nació para recuperar los "valores propios, las raíces, tanto africanas como americanas, como base para un sólido desarrollo cultural y político" (1998, p.108), según anota Rosalía Cortés en Identidad y literatura en el Caribe francófono. La invasión, enfatiza Cortés, les hizo tomar conciencia del desconocimiento del país real y de la necesidad de estudiar su lengua, sus creencias y la naturaleza misma para valorarlo y orientar la resistencia organizada. Roumain mismo, practicante de la etnografía, asumió la tarea de recorrer Haití, de ir al encuentro de una cultura que ignoraba. Así, la cultura del campo haitiano y los problemas sociales y políticos de los negros le suministraron los materiales que habría de utilizar, años más tarde, en la concepción y escritura de Gobernadores del rocío, obra que concluyó en México y que fue publicada en 1944, poco después de su muerte, ocurrida el 18 de agosto del mismo año en Haití.

Jacques Roumain, además de etnólogo y escritor, tenía una formación marxista, hecho que hacía de él un indigenista de otro tipo, más objetivo y crítico. El marxismo será para él, como para muchos intelectuales negros de la época, una fuente válida para entender y transformar las sociedades negras y mulatas. Es una lucha más amplia la que propone, según M. Ascencio, que incluye a todos los condenados de la tierra y no solo a los negros de Haití y el Caribe.

Como muchos de los intelectuales negros de los años treinta, Roumain encuentra en el marxismo la explicación y la única vía de salida de los negros norteamericanos explotados y discriminados por la sociedad blanca, de los antillanos asimilados y de los africanos recién colonizados. Sus lecturas, su amistad con Langston Hughes y Nicolás Guillén, sus reflexiones sobre la realidad haitiana a la luz del marxismo, lo diferencia de los otros intelectuales indigenistas de Haití y lo lleva a salirse del patio de su propia casa para solidarizarse con los 'negros pata en el suelo' de Haití y con todos los condenados de la tierra.' (2004, pp.XIV-XV) 
Aunque el marxismo de Roumain distó de ser muy sólido, el conocimiento que del mismo adquiriera en sus recorridos por Estados Unidos y México, le sirvió para entender los riesgos de la exaltación indigenista y las limitaciones de la ideología de la negritud, apostando por una forma de lucha más amplia, que correspondía librar a los proletarios del mundo entero, es decir, a todos los explotados del sistema capitalista, incluidos los negros.

\section{Gobernadores del rocío}

Es indisimulable que Jacques Roumain construye Gobernadores del rocio (1944) a partir de sus amplios conocimientos etnológicos, de la situación de crisis del campo haitiano y movilizado por el deseo de ofrecer a los negros y explotados de su país una salida liberadora, que les ayudara a superar sus disputas internas y a reconsiderar sus tradiciones culturales y mágicas como el vudú. Los trazos etnográficos son notorios y están presentes en las descripciones de las ceremonias como el vudú, el entierro de Manuel y los cantos del cumbite con el que cierra la novela. Su pensamiento político de izquierda, a favor del socialismo, marca de manera precisa la obra, algo comprensible en un intelectual que tiene la doble condición de escritor y militante político, pero el discurso ideológico del autor no obstruye los otros discursos del mundo recreado.

Sobre la intención política de la novela no queda ninguna duda, como tampoco de la notación política de izquierda del autor, reconocido dirigente comunista. Sobre la calificación de la novela como una obra al servicio de la causa del pueblo, vale traer una cita de Nicolás Guillén, tomada del prólogo que escribió para la edición cubana de 1971:

Su novela póstuma, Gobernadores del rocío, tiene por asunto la vida de los campesinos haitianos. En ella alcanza Roumain el punto más alto en su concepción de la literatura como un medio de servicio popular, y en todo caso de expresión humana, antes que simple juego y puro pasatiempo. (1971, p.XI)

La novela, además de denunciar la situación de los negros y retratar sus fisuras internas, enfrenta el papel inmovilizador del vudú y deriva en un alegato a favor del poder político de una institución comunitaria como el cumbite, llamada a articular la lucha en el campo haitiano y de conducirla a expresiones más complejas. Es una obra que participa del realismo social de una manera crítica, lúdica, compleja, en lugar de servir de simple medio de denuncia, como sucedió 
con muchas novelas escritas por esta época en varios países del continente, que sucumbieron al puro afán de denuncia, derivando en la obra cartel sin ninguna trascendencia. Su factura literaria la aparta, para algunos estudiosos de la obra, del llamado realismo crítico, inaugurando, para Jacques S. Alexis, algo que denominó "realismo simbólico". Según Michaelle Ascencio, citando a Alexis, esta concepción del realismo quedaría expresada en una obra que sería "una especie de gran poema popular de contornos clásicos y de personajes simbólicos", arquetípicos, como Manuel y la misma Anaísa, refiguración de Adán y Eva, la mítica pareja del paraíso judeocristiano.

La novela hace de una comunidad negra, la de Fonds Rouge, un gran personaje colectivo al denunciar su pobreza, al examinar el colapso de su economía debido a la tala de bosques, al verificar su sometimiento a las autoridades mulatas y los especuladores, trazando un fresco que ahonda en sus expresiones populares como el vudú, los cuentos y las adivinanzas y que, al mismo tiempo, señala las fisuras al interior de la misma, con familias separadas por la sangre y el odio, fuerza esta que tiene el poder de desarticularlos justo cuando más necesitan unirse para hacer frente a la sequía y el hambre que los cercan. Es una obra que, si bien exalta el ingenio de los negros, no oculta las contradicciones que los agobian, ni la forma en que la creencia en la intercesión o abandono de los dioses, contribuyen a paralizarlos y sumirlos en la resignación y la espera milagrosa de la lluvia que pondrá fin a la sequía y el hambre. Manuel, a su regreso de Cuba, será el personaje que desnude la resignación y la desunión de una comunidad aferrada a creencias que, sin ignorar su valor ritual y peso en la vida cotidiana de la comunidad, en nada contribuyen a solucionar los problemas que los amenaza de extinción.

La obra no es la pura y simple reivindicación ontológica del negro y la revaloración ciega de su cultura. La de Roumain es la visión de un crítico, artista y político consciente de la fuerza de la cultura popular, pero también de las limitaciones del vudú y el cumbite a la hora de romper con la explotación capitalista de los campesinos haitianos y de los explotados del Caribe. El cumbite tiene un valor relativo, válido en ciertos espacios y dimensiones. La lucha total, plena, contra la explotación, exige otras nociones y prácticas. Marxista, agitador y fundador de un partido de izquierda, resulta natural que la práctica ideológica conduzca a Roumain a examinar con cuidado el sistema de creencias de la cultura popular haitiana. Manuel (analfabeta aunque curtido en la lucha sindical en Cuba), es el espejo que le permite reflexionar creativamente sobre el bloqueo comunitario al que pueden conducir el vudú y la creencia en la intervención de las divinidades. Empobrecida, víctima de la sequía y el odio, la comunidad espera que sus loas 
intercedan por ellos. Frente a esta situación, Manuel propone otras alternativas: buscar el agua, aceptar la responsabilidad que quepa en la tala y superar la crisis de sequía mediante el trabajo comunitario, siendo para ello imprescindible la paz entre las familias enemistadas a causa de una mortal disputa de tierras, acto de sangre sucedido en su ausencia, en plena ocupación norteamericana.

Este episodio de la muerte del padre Gervilen por Salvador, hermano de Bienamé, es referida por este a Manuel con una sabiduría narrativa que ilustra, de paso, el vigor de la cultura popular haitiana y evidencia la indudable maestría de la prosa de Roumain:

Ellos estaban en pleno cumbite, Dorisca y su banda, y no habían mezquinado el clerén. Mi hermano, el difunto Salvador Juan José, que Dios tenga piedad de su alma, no siendo capón, se acerca el primero: Compadre Dorisca, dice, no has actuado en tu derecho. Pero Dorisca le responde: Apártate de mi tierra, o voy a cortarte que hasta los perros van a vomitar. Entonces, me injurias, dice el difunto Salvador. Mierda, responde Dorisca y tu mamá esto y tu mamá aquello. No debías haberlo dicho, hace Salvador y saca su machete antes que el otro y lo tiende duro, muerto. (1971, p.64)

Aunque un juez repartió las tierras, el acto mortal y la muerte de Salvador en una cárcel, dividen a la comunidad. Tierra y odio son repartidos para mal de todos. La voz del áspero y quisquilloso Bienamé es contundente sobre los estragos del odio, en una clara advertencia del poder de la sangre derramada: "Cada uno guarda su rencor y pule su cólera. Estamos nosotros y están los otros. Y entre los dos: la sangre. No se puede pasar sobre la sangre" (p.64). Es un hecho lamentable, pero, bien enterado de su papel, Manuel sabe que ahora tiene un nuevo enemigo contra el que pelear: el odio, y la llave para salvarlo y lavar la sangre, tiene que ser el agua, cuya búsqueda adelanta con gran empeño y total silencio. “...Manuel se iba lentamente hacia los campos, caminaba al sol, aplastaba las plantas marchitas y encorvaba un poco la espalda como si llevara una carga" (p.65).

\section{Negritud, vudú y cumbite}

\section{Negritud}

El Indigenismo en Roumain es un llamado a la lucha contra la explotación del 
campesinado y el proletariado en Haití y, por extensión, en otros países de mayoría negra. Manuel, el héroe, es el portador de esta ideología. Aunque analfabeta, igual que Cristo, regresa a la aldea natal para pregonar con el ejemplo la buena nueva. Igual que el rabí de Galilea, Manuel será sacrificado y aceptará el sacrificio como el precio de la reconciliación. Su reino, sin embargo, es de este mundo, en el aquí y un futuro probable.

Manuel regresa a su tierra con el propósito de quedarse y transformarse en el líder de la comunidad. La sequía y la desunión le ofrecen dos campos de acción inmediatos a los que consagra sus solitarios esfuerzos. Sirve esta situación para que comparta con el primo Laurélien preocupaciones sobre la identidad, la situación del negro y el papel político de estos.

Es un muchacho que, como resultado de la lucha sindical y política en Cuba, ha adquirido conocimientos sobre la situación del negro en el Caribe. Sobre Haití, su país, no tiene ninguna duda: "Este país es patrimonio de los hombres negros y todas las veces que trataron de quitárnosla (la tierra) hemos escardado la injusticia a machetazos" (p.82). Sabe que en Cuba y Haití el juez de paz, la policía rural y los especuladores de mercaderías, están encima de los negros. Son estos los explotadores: los enemigos. A la pregunta de Laurélien sobre lo que son ellos, los negros, tiene una respuesta certera. “...Somos este país y él no es nada sin nosotros" (p.83), pero es consciente de que la ignorancia política priva a los negros de ser una fuerza vencedora: "Algún día, cuando hayamos comprendido esta verdad, nos levantaremos de un extremo a otro del país y haremos la asamblea general de los gobernadores del rocío, el gran cumbite de los trabajadores de la tierra para extirpar la miseria y plantar la vida nueva" (p.83). El que habla, reflexiona y adoctrina es un cuadro político, alguien dueño de la misión de contribuir con el ejemplo a la desalienación de su comunidad.

Roumain entiende la negritud como una fuerza que es necesario despertar y organizar para hacer de la vida del negro y del país algo diferente. Su propósito, en este sentido, está a tono con los esfuerzos de los intelectuales y artistas que avivan la negritud en el Caribe. Sabe bien, como lo promovían Aimé Césaire y otros, que la negritud "es, ante todo, según mi opinión, una toma de conciencia concreta y no abstracta" (1969, p.XXX). Despertar y descolonización de la conciencia son vitales para que el negro asuma la tarea de su liberación económica, política y cultural. Manuel tiene claro que el propósito de la lucha trasciende la discriminación racial. Es un cuadro político que tiene identificados a los enemigos: la oligarquía mulata, el Estado rapaz, sus gendarmes, los comerciantes especuladores y el imperialismo, siempre amenazante. 
La negritud percibida en la obra es, por contexto y propósito, opuesta a la que pregonará el movimiento de la Negritud en los años posteriores al Indigenismo. La lucha del negro haitiano y de los negros tiene como objetivo final la construcción de la libertad y de una nación justa. No es una negritud o pre-negritud interesada en ensalzar la historia del negro frente a la del blanco, como aclara Ascencio en el Prólogo (XXVII) a la edición de la novela publicada por la Biblioteca Ayacucho. Es una negritud que muestra la explotación del negro, pero que percibe o intuye que esta lucha es un momento de la liberación mayor de todos los explotados del capitalismo y los sistemas coloniales vigentes, sin ningún distingo de color. Postura coherente y dialéctica de alguien que entendió a partir del marxismo básico al que al parecer tuvo acceso, que el fetiche de la epidermis es un hijo de capital, como tendrá oportunidad de esclarecer años más tarde René Dépestre al identificar las fuentes históricas de la discriminación racial en su ensayo Buenos días y adiós a la negritud.

El fetichismo de la epidermis es un hijo político del capital. Detrás de él se proyecta la sombra dirigida, alienante y prepotente de la propiedad privada; la situación objetiva de un tipo social de hombres, los amos europeos, que redujeron al estado de propiedades a otro tipo social de hombres, los esclavos africanos, no a causa de una 'diferencia de naturaleza, de raza o de especie' entre los primeros y los segundos, sino, simplemente, porque en la escena política y militar del siglo XV, la religión de la fuerza era favorable a los Estados cristianos de Occidente, a la hora de remplazar, en las minas y en las plantaciones de América, a los trabajadores indios por los trabajadores africanos. (1996, p.93)

\section{El vudú}

El vudú es una fuerza ancestral, un sistema mágico-religioso de cohesión, una práctica viva de la religiosidad de Fonds Rouge, pero al mismo tiempo es una fuente de resignación que priva al hombre de la lucha y lo entrega a los rigores de la naturaleza y a un sistema de explotación como el capitalismo.

En la novela, el vudú entra de manera natural, en tanto es un reflejo de la conciencia mágico-religiosa del pueblo haitiano, como advierte Margarita Mateo en su artículo Narrativa caribeña: reflexiones y pronósticos (1990), en el que examina el papel de la dimensión mítica en la novela de Roumain. 
El vudú incorporado de esa forma en la obra trasciende el simple uso especular de un mito. Para la autora, el vudú desempeña en la obra una eficaz función narrativa clave en tanto expresión de las creencias y la concepción del pueblo haitiano. Práctica que Roumain entiende y conoce, si bien resulta contraria a los dictados de la lucha política de izquierda que profesa.

Manuel, el personaje central, será el encargado de explicitar la actitud de incredulidad y rechazo hacia el vudú. En la novela el vudú irrumpe en el capítulo IV, cuando Délira y Bienamé, contratan a Dorméus, el hungan, para realizar una ceremonia de agradecimiento por el regreso del hijo.

La ceremonia cambia de signo cuando Papa Legba, el dios que abrió el camino de regreso a Manuel, es sustituido por Ogún, el sanguinario y temido dios de los herreros. A ello hay que agregar que Manuel, al ser interrogado por Ogún, olvida las fórmulas de respeto debida a los loas.

Según la lectura mágica de la novela, en la perspectiva de las creencias del pueblo haitiano, la aparición de Ogún y el canto de muerte con el que concluye el ritual, adquieren un significativo valor profético. La muerte de Manuel, anunciada de esta forma, significaría también una sanción por su irrespeto a las divinidades afroantillanas, según la postura de Mateo $(190,83)$; anuncio, sugerencia que solo Délira capta: "Bienamé, mi hombre. No me gusta eso que ha cantado Papa Ogún, no. Sentí un peso en el corazón. No sé lo que me pasa” (p.77).

A todas estas, hay que señalar, que Manuel, ajeno al presagio y a su recepción por parte de Délira, mantendrá una actitud de crítica sobre el ritual y la fiesta en la que culmina:

Sin embargo, la fiesta continuaba. Los vecinos olvidaban su miseria la danza y el alcohol los anestesiaba, los arrastraba y ahogaba su conciencia náufraga en esas regiones irreales y sombrías donde los acechaba la ferocidad irracional de los dioses africanos. (p.78)

$\mathrm{Su}$ actitud es reflexiva frente a la práctica que ha costado cuarenta piastras de la economía doméstica. Reflexión que adquirirá un carácter más abierto durante su cita con Anaísa en el monte de los lataneros, la que tiene lugar varios días después del ritual. Es terriblemente crítico de su comunidad: 


\begin{abstract}
¿Cómo viven ustedes? Sería un milagro que viviesen, pero esto es morir, ustedes morirán lentamente. ¿Y qué han hecho contra esto? Una sola cosa: gritar vuestra miseria a los loas, ofreciendo ceremonias para que ellos hagan caer la lluvia. Pero todo eso son idioteces y macaquerías. Eso no cuenta, es un despilfarro inútil. (p.102)
\end{abstract}

Al ser interrogado por la muchacha sobre el temor a los viejos de Guinea, su respuesta ilustra el valor que para él tiene el vudú.

No, tengo consideración por las costumbres de los antepasados, pero la sangre de un gallo o de un cabrito no puede dar vuelta a las estaciones, cambiar el curso de las nubes e hincharlas de agua como vejigas. La otra noche, en ese servicio de Legba, bailé y canté mi plena satisfacción: soy negro, ¿no es cierto?, y me di el gusto como negro verdadero. Cuando los tambores golpean, me repercute en la boca del estómago, siento una comezón en mis riñones y una corriente en mis piernas, es preciso que entre en la ronda. Pero eso es todo. (p.102)

Aquí en este apartado de la novela, sin ninguna duda una de sus cimas, Manuel reconoce que su experiencia de Cuba le enseñó que la rebeldía y el conocimiento de que el hombre es el modelador de su vida, son las cosas que cuentan. Cree en la huelga, de la que participó en los ingenios de Cuba y cree, además, en el conocimiento sobre la tierra y la naturaleza, que le permitirá encontrar el agua y colocarla al servicio de todos. El agua será para todos y entre todos construirán el canal que habrá de traerla a la llanura calcinada, en cuyos huertos y campos mueren la tierra talada y en la que ellos sobreviven. Pero el cumbite no es posible si persiste la enemistad, el odio, y si el odio persiste, el agua se quedará sin utilidad para nadie.

El vudú es una creencia sin ninguna fuerza para alterar la sequía y solucionar la miseria y la explotación. Es una fuerza inmovilizadora, que lastra y resigna, según el protagonista. El cumbite, en cambio, es la fuerza comunitaria que permitirá desplegar la lucha en principio contra la pobreza.

El vudú, si bien contrario a la ideología de Manuel y a la ideología del autor, cumple en la novela un papel narrativo crucial desde el punto de vista del pen- 
samiento precientífico y popular de la comunidad que asiste a la ceremonia en casa de Bienamé y Délira, los padres de Manuel. La función que el vudú cumple sería, para Margarita Mateo, una lección de eficaz uso literario de la dimensión mágico-religiosa del pueblo haitiano en la novela. Más que pintura, que simple artilugio folclórico, el ritual devela, además de conocimiento, un uso estético acertado y consciente que sirve de contrabalanceo a la mirada externa del protagonista.

Para Margarita Mateo (1990) es claro que la dimensión mítica de la novela, expresada en el vudú, en nada afecta la eficacia de su mensaje comunitario y socialista, y contribuye más bien a su mejor elaboración artística. Aunque para Roumain la religión constituía una traba para el progreso de Haití, no por ello, en tanto creador y etnólogo, relegó el vudú, sino que, afincado en su conocimiento de la práctica, la empleó con indudable eficacia literaria en la obra.

\section{El cumbite}

El cumbite, en este sentido, es la institución que Roumain, siempre a través de Manuel, su alter ego en la ficción, reivindica, en la que ve la salida al odio que divide a los hombres y mujeres de Fonds Rouge y a la crisis de sequía; por ello, cuando descubre la fuente de agua que traerá la vida a los campos de su aldea, sabe que la única manera de aprovecharla es mediante un gran cumbite, es decir, mediante el trabajo de toda la colectividad, sin ningún reparo, de ahí que sea él quien proponga a la familia enemiga y la suya la paz, y les haga extensiva la invitación a todos a salvarse mediante el esfuerzo articulado. Para él, sin embargo, este es un primer paso, porque es claro, como queda sugerido en sus conversaciones con Anaísa, que sus propósitos con la comunidad van más allá. Esto es evidente cuando reflexiona sobre la conveniencia de unirse todos contra los explotadores y además por el papel que le asigna a la educación para las futuras generaciones, para que estas no vivan en la ignorancia que frustra, atemoriza e inmoviliza. Es un actor político el que habla, así a ratos Jacques Roumain, el cuadro marxista, hable por él, en una indisimulable identificación ideológica entre el autor y su personaje. Indigenismo beligerante, que cree en el poder de la educación, la literatura, la ciencia, e inseparable de la lucha ideológica y política contra el explotador, que acude de manera inteligente al cumbite como institución colectiva y tradicional a partir de la cual comenzar a organizar la confrontación política: lucha que no podía excluir a los sectores pobres de las ciudades y a los mulatos marginados que laboraban en actividades informales, domésticas y de baja remuneración en Haití. 


\section{EI socialismo: una apuesta en el horizonte}

La novela firma un dibujo que trasciende el ámbito del cumbite. Es una propuesta para que los negros superen sus diferencias y aprendan, desde sus posiciones en la producción y las clases a identificar a sus enemigos. Manuel sabe que el odio es nefasto porque aísla, separa, inmoviliza; de ahí la necesidad de alcanzar la paz entre su familia y la de Gervilen, para allanar el camino del cumbite y, a partir de este, de otras formas de lucha. La razón y el entendimiento deben guiar el proceso de superación de la crisis social y económica de Fonds Rouge. El socialismo pareciera ser el camino hacia el que la novela orienta. Algo normal en un continente en que hacían irrupción los partidos de izquierda. El propio Jacques Roumain había fundado el Partido Comunista de Haití en 1934. Era estratégico que, como paso previo a la lucha contra el capital y la explotación, el negro haitiano debía superar sus rencillas internas. Los negros, al menos en Haití, constituían una clase marginada, oprimida, a la que se le negaba la educación y que vivía a expensas de las autoridades y los mulatos. Durante la invasión norteamericana los negros fueron las víctimas de la alianza entre invasores y la burguesía mulata. Habían perdido sus tierras, habían tenido que convertir sus bosques en carbón, marchar a las ciudades o a otros países como sucedió con Manuel. Correspondía organizarlos, educarlos políticamente, para usar su gran fuerza contra la dominación y construir, en un futuro que muchos visualizaron en el horizonte inmediato, una nación sin explotadores y explotados. Esta visión, un tanto romántica, y la jerga que Manuel emplea, no admiten dudas de los alcances del discurso de la novela, de la motivación ideológica del autor, expresión de los sectores más oprimidos del Caribe y el continente en ese entonces. Su negritud es materialista, histórica, concreta, una ideología que sabe dónde están los amigos y dónde los enemigos. $\mathrm{Su}$ formación sindical le alcanza para saber que existen negros y mulatos, y que tales diferencias responden a los lugares que unos y otros han desempeñado históricamente en la producción y distribución de bienes materiales y espirituales. Son adversarios, no por el color, sino por el lugar que ocupan en la producción y en la sociedad. La suya es, en síntesis, una negritud materialista y consciente de que en la lucha de liberación los negros son una clase de oprimidos y nos los únicos. A la influencia del socialismo, a la formación marxista del autor, habrá que atribuir que la negritud de Gobernadores del rocío escape a la metafísica somática en la que terminó evaporada la negritud al derivar en ideología de Estado y caer en las trampas del imperialismo metodológico de la antropología cultural y del concepto de raza que pensó combatir, como lo ha elucidado sistemática y convenientemente René Dépestre en su citado artículo Buenos días y adiós a la negritud. Por ello, el discurso que anima a Gobernadores del rocio, a prudente distancia de la negritud esencialista, tiene claro el camino a transitar: 
No hay más que un medio para salvarnos, uno solo, no dos: reconstruir la buena familia de vecinos, rehacer la unión de los trabajadores de la tierra entre hermanos y hermanos, compartir nuestras penas y nuestro trabajo entre camaradas y camaradas... (p.156)

Es un discurso consciente al invocar el espíritu comunitario de Fonds Rouge: el cumbite. Es consciente, asimismo, que el cumbite es solo la plataforma de una lucha más amplia, que deben desarrollar los campesinos explotados por un sistema que los deshumaniza para justificar su dominio sobre ellos y sus recursos. La novela es, en la perspectiva del indigenismo y la negritud, más que una fuente de conocimiento de comunidad, un instrumento de lucha, además de ser la expresión estética del ingenio popular de una etnia satanizada. La cultura popular deriva en una fuente disponible, que "está en nosotros como una punzada y una esperanza, pero también como conciencia o locura de una carencia”, para usar las palabras que E. Glissant emplea en El discurso antillano (1981, p.174) al referirse a una probable salida a la situación de alienación integral de los negros de Martinica.

El cumbite debía trascender hasta transformarse en un cumbite de todos los trabajadores del mundo, sistema que permitiría formar la asamblea general de gobernadores del rocío, el gran cumbite que extirparía de la miseria de la tierra y en su lugar plantaría una nueva vida.

En la ficción, ciertamente, el cumbite opera, y la muerte de Manuel, herido por el brazo nocturno de Gervilen, no impide que la comunidad construya el canal que acaso devuelva la prosperidad a las tierras del empobrecido fundo.

Un exceso de idealismo y hasta de misticismo podría objetársele a la novela, si uno emparenta el sacrificio de Manuel con el sacrificio de Cristo, cuyo mito está en la trastienda de la vida del protagonista desde su regreso de $\mathrm{Cuba}^{2}$. Manuel es, sin embargo, un Jesús en el que el discurso cristiano cede el lugar al discurso del socialismo.

2 El mito de Jesús es notorio en la obra, un instrumento expresivo que la atraviesa y configura, según Margarita Mateo. La misión y sacrificio de Manuel sigue un camino similar al de Jesús. Los niños también sucumben al encanto de Manuel, el negro que vino de Cuba, que busca el agua. Este manejo acertado del mito cristiano en la refiguración de Manuel sería otra prueba de la importancia funcional, para Mateo, de la dimensión mítica y del empeño de Roumain por "alcanzar la imagen exacta de su pueblo" (p.90). La novela recrea otros mitos de la tradición judeo-cristiana como la pareja de Adán y Eva, de alguna manera refigurada en Manuel y Anaísa. 
Es un hombre que tiene plena certeza terrenal de su destino y del sentido de su sacrificio. En el lecho de moribundo, en la compañía cómplice de Délira, deja todo dispuesto para que ella no solo oculte la real causa de su muerte, sino transmita un mensaje de reconciliación a la familia del agresor, a efectos de que el agua y la comunidad se salven:

Habéis ofrecido sacrificios a los loas, habéis ofrecido la sangre de las gallinas y los cabritos para hacer que caiga la lluvia, eso no ha servido para nada. Porque lo que cuenta es el sacrificio del hombre. Es la sangre del negro. Ve a buscar a Larivoire. Dile la voluntad de la sangre que ha corrido: la reconciliación, la reconciliación para que la vida recomience, para que el día se eleve sobre el rocío. (p.206)

Solo este sacrificio permitirá a su comunidad transformarse en gobernadores del rocío, del agua, del riego.

La ideología de Roumain, encarnada en Manuel, aunque crítica de la realidad social del negro haitiano, está lejos de ser un impedimento a la hora de enfrentar y entender el vudú como una creencia presente en la vida cotidiana del campesinado haitiano. Según la lectura de Margarita Mateo, la habilidad del creador que había en Roumain consistió en incorporar el vudú como un eficaz procedimiento narrativo, como una función estructuradora que para ella va a ser una característica central de la literatura caribeña de la segunda mitad del siglo XX. Eludió así la trampa de la novela realista de la época de incorporar los mitos como simple reflejo especular. El efecto es una obra compleja en donde la ideología socialista admite en la novela otras ideologías y creencias operantes en la sociedad recreada, el sustrato vital y último de toda obra de creación.

Haití sigue siendo una nación atrapada en el odio, la pobreza, la corrupción, las guerras internas, un pedazo de tierra que la naturaleza sacude de cuando en cuando, como sucedió hará dos años con el terremoto que acabó con parte del país y mató a miles de haitianos. El socialismo, la esperanza de Roumain, probó ser un sistema despótico en manos de hombres como Stalin. No vivió para conocer los horrores del stalinismo, que motivaría la renuncia de Aimé Césaire al Partido Comunista de su país a mediados de los cincuenta, pero sí padeció el callejón sin salida en el que todavía deambula Haití.

Cabe la posibilidad de ver en la mano oscura y letal de Gervilen la metáfora y 
representación de esas fuerzas internas dispuestas siempre a borrar el camino del entendimiento y a liquidar a los hombres que piensan diferente. A Roumain le sucedió. Ser comunista y entender de otra manera Haití le valió persecuciones y cárceles. Acaso al político inspirado, el ojo escéptico del poeta le sugirió, en algún momento de la concepción de la novela y su héroe sacrificado, que hace falta algo más que sueños para cambiar la historia, porque en cada vuelta del camino hay un Gervilen dispuesto a emerger de las sombras con un golpe de puñal. Queda, dirá alguna voz, la esperanza, una fuerza, una carencia, un camino susceptible de ser afrontado una y otra vez, a cualquiera hora, bajo la tormenta y el agua, a oscuras, si es preciso.

\section{Referencias bibliográficas}

Ascencio, M. (2004). Prólogo. En Gobernadores del rocío y otros textos, 215. Caracas: Biblioteca Ayacucho, IX-XXVIII.

Cortés, R. (1998). Identidad y cultura en el Caribe francófono (ensayo). Cuadernos de literatura, 107-118.

Depestre, R. (1996). Buenos días y adiós a la negritud (ensayo). En López Laura (ed). Literatura francófona II. México: FCE.

Depestre, R. (1969). (Entrevista a Aimé Césaire). En Poesías. Aimé Césaire. La Habana: Casa de las Américas. XVIII-XXXIII.

Glissant, É. (2010). El discurso antillano (ensayos, 1981). La Habana: Casa de las Américas, 158-176.

Guillen, N. (1971). Prólogo: En: Gobernadores del rocío. La Habana: Casa de las Américas, VII-XI.

Mateo, M. (1990). Gobernadores del rocío: Una dimensión mítica. En: Narrativa caribeña: reflexiones y pronósticos (pp.79-91). La Habana: Editorial Pueblo y Educación.

Roumain, J. (1971). Gobernadores del rocío. La Habana: Casa de las Américas. Valero, A. (2005). El rostro imaginado: representaciones de la comunidad haitiana. En Contexto, 9(11), 151-167.

Cómo citar este artículo: Ramírez, C. \& Noriega, I. (2017). Negritud, cumbite y socialismo en Gobernadores del rocio, de Jacques Roumain. Cuadernos de Literatura, (25), 75-92. DOI: http://dx.doi.org/10.15648/c1.25.2017.5 